\title{
Gestão de águas urbanas em Belo Horizonte: avanços e retrocessos
}

\section{Valdete Lima Bontempo, Cindy Olivier, Carla Wstane de Souza Moreira, Gabriel Oliveira}

RESUMO: Ao buscar uma consonância com novos modelos de gestão de recursos hídricos no âmbito de áreas urbanas, Belo Horizonte destacou-se no cenário latinoamericano pela linha adotada no Programa DRENURBS. Sua proposta de revitalização de rios/córregos visa incluir os cursos d'água na paisagem da cidade, mantendo-os em leito natural, o que indica uma mudança significativa na política de saneamento urbano ao mesmo tempo em que valoriza as expectativas das populaçóes ribeirinhas. Mas, apesar de suas inovações conceituais, algumas dificuldades foram verificadas no curso da implantação do programa, além da implantação simultânea do Projeto Boulevard Arrudas, que, em total contradição com as diretrizes do DRENURBS, fecha o canal do principal rio que atravessa a cidade de Belo Horizonte. Este artigo propóe realizar uma análise desses dois projetos, de propostas antagônicas, refletindo sobre as dificuldades encontradas na realização das intervenções do DRENURBS e sobre as resistências contra a adoção de um novo paradigma de gestão de águas urbanas.

PALAVRAS-CHAVES: Gestão de recursos hídricos, drenagem urbana, revitalização de rios
ABSTRACT: Seeking consonance with new models of water management within urban areas, Belo Horizonte stands out in Latin America due to the policies adopted on DRENURBS Program. Its proposal for recovering rivers and creeks aims to include watercourses in the city landscape, keeping them in natural beds. It indicates a significant change in sanitation policies and at the same time values the expectations of people who live near the creeks. Despite the conceptual innovations of this Program, some difficulties were found in their development, besides the simultaneous implementation of Boulevard Arrudas Project that closes the main city river. This paper proposes to perform an analysis of these two antagonistic projects, reflecting on the difficulties experienced by DRENURBS during its interventions and the resistances to the adoption of a new paradigm in urban water management.

KEY-WORDS: Water resources management, urban drainage, revitalization of rivers

\section{INTRODUÇÃO}

Nos últimos anos, vários avanços vêm sendo alcançados na área da política ambiental no Brasil, ancorados no discurso do desenvolvimento sustentável e na medida em que o nível de participaçáo e envolvimento da população se incrementa, se autovaloriza e, principalmente, se faz presente junto às tomadas de decisões do Poder Público.

No que se refere à gestáo de recursos hídricos no Brasil, os novos modelos de gerenciamento dos rios urbanos buscam soluçóes de drenagem com enfoque integrado, procurando manter o curso d'água em seu leito natural, despoluindo suas águas e revitalizando seu entorno. Incluem também, conforme preconiza a Política Nacional de Recursos Hídricos ${ }^{1}$, uma parceria

${ }^{1}$ Também chamada de Lei das Águas, a Lei $9.433 / 97$ substituiu entre o Poder Público, os usuários e as comunidades locais, propondo o equilíbrio entre os requisitos técnicos das obras e as expectativas sociais da população em geral (Brasil, 1997). Tais avanços trazem consigo desafios, impasses, dificuldades e inúmeros conflitos, quando são experimentados na arena do debate político e na prática das políticas ambientais, assim como nas intervençôes urbanas realizadas por órgãos públicos.

o antigo Código das Águas de 1934. Apesar de reconhecer o recurso hídrico como bem público, dotado de valor econômico, efetuou mudanças no âmbito de seu gerenciamento. Desde então, considera-se a gestão das águas como integrada (múltiplos usos), descentralizada (bacia hidrográfica como unidade de planejamento) e participativa (paridade entre os diferentes níveis do poder público e a sociedade civil). 
Nesse sentido, Belo Horizonte, capital do Estado de Minas Gerais, localizada no sudeste brasileiro, atualmente com uma população de 2375444 habitantes ${ }^{2}$, tem feito avanços por meio do Programa de Recuperação Ambiental de Belo Horizonte (DRENURBS), o qual assumiu o papel de reverter a atual situação de degradação dos cursos d'água, a partir da premissa de preservação e recuperação dos córregos/rios que ainda estão em leitos naturais, incluindo-os na paisagem urbana. O DRENURBS inova conceitualmente, caminhando em direção a uma mudança significativa na política de drenagem, ao deixar para trás um paradigma ultrapassado - o da canalização de rios.

O paradigma que se considera ultrapassado - mas que ainda é comumente usado no Brasil, apesar de já abandonado em vários outros países - fundamenta-se no conceito higienista voltado para a adoção de medidas estruturais no que se refere ao tratamento da drenagem urbana (Nascimento e Heller, 2005). O novo modelo proposto pelo DRENURBS pode ser considerado "renaturalizante", porque adota medidas não estruturais na gestáo da bacia hidrográfica, que favoreçam a volta da biota aquática e da mata ciliar.

Entretanto, a busca por mudanças encontra quase sempre um caminho tortuoso, tanto na conceituação como na prática. E também a gestão referente ao saneamento em Belo Horizonte encontra obstáculos e apresenta contradiçóes. São resistências manifestadas pelos próprios gestores e pela população, que está acostumada a ver a canalizaçáo como garantia de resolução dos problemas sanitários e de saúde pública.

Assim, apesar da implantação bem sucedida do DRENURBS em três bacias - dos Córregos $1^{\circ}$ de Maio, Baleares e Nossa Senhora da Piedade -, entendemos que o programa tem enfrentado dificuldades para se consolidar como modelo para a gestão de águas urbanas no município. Observa-se, por exemplo, que, paralelamente à implantação das primeiras intervenções do DRENURBS, pode-se acompanhar a execução do Boulevard Arrudas, com o fechamento do canal do rio de mesmo nome que percorre o centro da capital mineira, indicando a opção pela forma tradicional de saneamento e afastamento de quaisquer possibilidades de voltar a inseri-lo na paisagem urbana.

O presente artigo objetiva analisar essas dificuldades por meio do estudo da implantação do Progra${ }^{2}$ Conforme censo realizado pelo Instituto Brasileiro de
Geografia e Estatística (IBGE) em 2010. ma DRENURBS no âmbito da Bacia do Córrego Engenho Nogueira ${ }^{3}$, cujas obras foram concluídas em 2011, e realizar também uma reflexão sobre a implantação simultânea, em Belo Horizonte, de projetos com pressupostos tão divergentes na gestáo de recursos hídricos.

Apresentar-se-á, primeiramente, uma descrição geral do DRENURBS, seguida de explanaçóes sobre as intervençóes propostas para a Bacia do Córrego Engenho Nogueira, com destaque para as medidas já implantadas, bem como para as dificuldades encontradas nessa implantação. Posteriormente, discutiremos alguns dos elementos que configuram conflito na gestão das águas urbanas, pois a implantação simultânea do DRENURBS e do Boulevard Arrudas constitui um discurso controverso, em nome do interesse ambiental fundado na proposta de desenvolvimento sustentável ${ }^{4}$, a partir de interesses diversos e da incoerência no âmbito do Poder Público, que não pode ser visto como um bloco único.

\section{AS POSSIBILIDADES DE MUDANÇA DE PARADIGMA NA GESTÃO URBANA DE RECURSOS HÍDRICOS}

A canalização dos rios como forma de gestão das águas urbanas fundamenta-se numa visão higienista, onde a idéia é afastar o lixo, o mau cheiro e a poluição para locais distantes da cidade, especialmente de suas áreas centrais. Também tem a intenção de combater as enchentes e as inundaçóes. Entretanto, muitas vezes, a canalização pode produzir o efeito contrário, pois a retificação dos cursos d'água direciona e conduz de forma mais intensa o excesso de água a jusante, devido à redução das curvas naturais, o que aumenta a velocidade da água. Essa situaçáo explicita a necessidade de se pensar alternativas, como a revitalizaçáo de rios, para a redução dos riscos ambientais e hidrológicos aos quais a população local está exposta.

É importante compreender que essa perspectiva vem sendo aplicada há muito tempo na política ur-

\footnotetext{
${ }^{3}$ Foram escolhidos para integrar esse programa córregos e ribeirões de 47 bacias e sub-bacias em que o curso d'água principal apresentava-se total ou parcialmente em leito natural, em áreas de significativo adensamento. A Bacia do Córrego Engenho Nogueira foi um dos empreendimentos implantados na primeira etapa do programa.

${ }^{4} \mathrm{O}$ desenvolvimento sustentável faz referência à ideia de justiça entre os membros de uma mesma geração, entre as gerações e com relação à natureza (Britto e Barraqué, 2008).
} 
bana do Brasil, influenciada por conceitos trazidos da Europa desde o século XIX, os quais ainda estavam longe de incorporar uma perspectiva ambiental na gestão das cidades. $\mathrm{O}$ movimento sanitarista apareceu, ao longo da década de 1840-50, como reação ao quadro caótico de insalubridade existente nas grandes cidades da Inglaterra, e repercutiu gradativamente pela Europa e pelos Estados Unidos. No Brasil, esse modelo foi introduzido por Oswaldo Cruz, no início do século XX, no Rio de Janeiro, capital federal à época, e, apesar de ter alcançado resultados inquestionáveis em relação à saúde pública - no controle de epidemias, doenças infecciosas e na redução do índice de mortalidade infantil -, sua concepçáo atual precisa absorver a dimensão ambiental surgida nas últimas décadas.

A origem de Belo Horizonte, no final do século XIX, seguiu a lógica do planejamento e gestão das águas urbanas que privilegiava as canalizaçōes e não respeitava o traçado natural dos inúmeros cursos d'água existentes em seu território. Naquele tempo, o Estado brasileiro, como impulsionador do progresso, adotava os princípios positivistas herdados da revolução científica e industrial europeia, e começava a por em prática a concepção sanitarista e higienista nas intervençóes urbanas. Assim, no início da concepção do projeto urbano da nova capital, a canalizaçáo e o fechamento de córregos foram vistos como a alternativa ideal para economia de espaço, agilização do escoamento das águas e minimização do efeito das cheias.

Ao se analisar o traçado urbanístico feito por Aarão Reis, engenheiro-chefe da comissão que construiu Belo Horizonte, vêem-se avenidas em diagonais, nas quais já se pressupunha a importância que iria ter a canalização na capital mineira, pois os tributários do Ribeirão Arrudas não foram utilizados como referências naturais na composição do traçado da zona urbana, embora estivessem fisicamente presentes, cortando as ruas e os quarteirôes (Fundação João Pinheiro, 1997).

De fato, no decorrer do século XX, muitos dos córregos encontrados no município foram sendo canalizados, primeiro a céu aberto e, depois, aos poucos, cobertos por avenidas sanitárias mal planejadas, pois os esgotos eram despejados sem nenhum tratamento. A partir da década de 1950 e, essencialmente nos anos 70, com o crescimento demográfico acelerado, a economia de espaço que decorre da sobreposição de um curso d'água para implantar-se uma via pública foi (e ainda é) fator determinante na decisão de se canalizar os córregos/rios.
Atualmente, em Belo Horizonte, existem aproximadamente $673 \mathrm{~km}$ de cursos d'água, com 26\% deles revestidos $(173 \mathrm{~km}$ de canais em concreto armado). Os outros $500 \mathrm{~km}$ de córregos e ribeiróes continuam em seus leitos naturais, e desses, pouco mais de 200 km encontram-se situados nas áreas urbanizadas. $\mathrm{O}$ restante situa-se em regióes inadequadas ao parcelamento urbano ou em áreas de preservação permanente. O Programa DRENURBS contempla os cursos d'água em leito natural que se situam na mancha urbana, num total de 73 córregos e ribeiróes (PMBH, 2000).

O Guia de Plano Diretor Participativo do Ministério das Cidades (Brasil, 2004) trouxe algumas inovaçóes importantes, de caráter tecnológico, de planejamento e de gestáo dos sistemas de drenagem de água, que permitem diminuir problemas relacionados com inundaçóes e com a poluição difusa dos meios receptores. Uma grande contribuição dessas inovaçôes é a de se criar alternativas de valorização dos corpos d'água no contexto urbano e de ampliação dos espaços verdes e áreas de lazer nas cidades.

Algumas intervençôes estruturais aparecem como alternativas para o tratamento dos fundos de vales e para a recuperação dos cursos d'água, e seu objetivo inicial é reduzir os riscos e as consequências físicas, econômicas e sociais das inundaçóes por meio do controle e ocupação do solo. Esse novo tipo de gestáo das águas rompe com a perspectiva higienista, na medida em que a proteção ambiental e a valorização dos corpos d'água na paisagem urbana passam a ser compatibilizados com os objetivos funcionais do saneamento ambiental (drenagem das águas pluviais, redução de riscos à saúde, melhoria da qualidade de água), além de possibilitar a criação de parques lineares, restaurar e proteger a fauna e flora ribeirinhas, revitalizar as atividades econômicas locais, preservar e restaurar referências históricas e culturais (Brasil, 2004).

Em Belo Horizonte, a proposta de revitalização de rios surgiu a partir de uma modificação da Lei do Plano Diretor de Belo Horizonte (CMBH, 1996), que determinou a elaboração do Plano Diretor de Drenagem Urbana (PDDU). A partir desse plano, concluído em 2000, a prefeitura tomou a decisão de implementar açóes de melhoramento ambiental com ênfase na preservação dos cursos d'água em seu leito natural e conservação do seu entorno, ainda que estivessem degradados pela poluição e pela ocupação de suas margens. Tais açốes integram-se ao DRENURBS, lançado em 2001, com o objetivo geral de 
"promover a melhoria da qualidade de vida da população do Município, através de açóes de melhoramento ambiental, com ênfase na conservação de cursos d'água que, embora degradados pela poluição e pela invasáo de suas margens, conservam-se em seus leitos originais" (PMBH, 2002, p.12).

A seguir, será feita uma apresentação geral do Programa DRENURBS, com destaque para suas inovaçóes e para a forma como se deu sua implantação na Bacia do Córrego Engenho Nogueira.

\section{PROGRAMA DRENURBS NA BACIA DO CÓRREGO ENGENHO NOGUEIRA: AVANÇOS E LIMITAÇÕES}

O DRENURBS traz uma nova concepção de saneamento ambiental, ao propor a revitalização dos córregos existentes em áreas urbanas, com a descontaminação da água e a recomposição da mata ciliar, via eliminaçáo do despejo de efluentes no seu leito e a remoção e reassentamento das famílias instaladas nas várzeas. Tais intervençóes urbanas visam minimizar as fontes de doenças hídricas e inundaçóes, por meio da implantação de sistemas de interceptação de esgoto e de drenagem das águas pluviais. Também permitem a ampliação e o restabelecimento das faixas marginais, favorecendo a recuperação dos ecossistemas e a criação de áreas de uso social e paisagístico (parques lineares).

Para vencer o desafio da despoluição das águas urbanas, a Prefeitura de Belo Horizonte optou por soluçóes de longo prazo, divididas em etapas sucessivas, investindo em parcerias para o financiamento das obras. A primeira etapa do DRENURBS reuniu cinco áreas de trabalho - as bacias hidrográficas dos Córregos $1^{\circ}$ de Maio, Baleares, Nossa Senhora da Piedade, Engenho Nogueira e Bonsucesso - a um custo de US\$ 77,50 milhóes, dos quais US\$ 46,50 milhôes foram financiados pelo Banco Interamericano de Desenvolvimento e o restante (US\$ 31,00 milhóes) representou a contrapartida local. Essa etapa beneficiou diretamente uma populaçáo de cerca de 67 mil habitantes e aproximadamente $28 \mathrm{~km}$ de cursos d’água (PMBH, 2002).

As principais intervenções realizadas foram a interceptação de esgotos, o tratamento e a recuperação das margens dos córregos, a implantação de reservatórios para o controle de inundaçôes, a ampliação dos sistemas de limpeza urbana, a conservação de nascentes, a recomposição da vegetação, a desapropriação de imóveis, a relocalização de famílias que viviam em locais de risco ou que sofreriam interferência direta das obras, e, finalmente, o desenvolvimento de planos locais de educação ambiental e mobilização social.

Nesse ponto, é preciso destacar que o processo participativo adotado pelo DRENURBS na gestão de águas urbanas, visto como uma ação integradora, é considerado inovador no Brasil. A parceria entre gestores e comunidades locais parte do princípio de que uma intervenção urbana no espaço deve ancorar-se, primordialmente, nas formas de uso e apropriação do lugar. Conforme colocado por Souza (2001), tais estratégias e açóes contribuem para minimizar certas fontes de distorção. Além disso, o cidadão que participa de uma decisão, sente-se mais responsável pelo seu resultado, fica predisposto a cuidar mais e fiscalizar melhor, com um sentimento de pertencimento, que o leva a se responsabilizar pelo lugar, apropriando-se das intervençôes no espaço público para que as mesmas não sejam abandonadas.

A gestão participativa proposta pelo DRENURBS tem o intuito de valorizar as peculiaridades de cada bacia/sub-bacia e de interagir com todos os segmentos sociais envolvidos, construindo conjuntamente os planos de educação ambiental e de mobilização e comunicação social, para o envolvimento e fortalecimento comunitário. Nesse sentido, o programa criou a Comissão Comunitária Local (Comissão DRENURBS), a qual participa da elaboração e do acompanhamento das diversas atividades e produtos propostos pelos planos.

Nos três primeiros empreendimentos - bacias dos Córregos $1^{\circ}$ de Maio, Baleares e Nossa Senhora da Piedade-, várias atividades foram realizadas durante a execução das obras de revitalização dos cursos d'água, tais como palestras para a reflexão sobre temas relevantes na defesa da qualidade ambiental do espaço urbano (gestão de bacias hidrográficas, disposição de resíduos sólidos, saúde pública, etc.), visitas técnicas aos locais com experiências positivas em relação ao tratamento das questôes socioambientais (aterro sanitário, estação de tratamento de esgoto, associação de catadores de materiais recicláveis e parques urbanos), implantação de projetos de sensibilização nas escolas (apresentaçôes teatrais), caminhadas de percepção ambiental, oficinas de reutilização de materiais recicláveis e plantio simbólico de mudas na área do parque (Costa et al, 2008).

No caso específico da Bacia do Córrego Engenho Nogueira $^{5}$, deve-se esclarecer que a extensão de seus

${ }^{5} \mathrm{~A}$ Bacia do Córrego Engenho Nogueira situa-se na margem 


\section{FIGURA 1: Intervenções realizadas pelo DRENURBS na Bacia do Córrego Engenho Nogueira Fonte: Unidade de Execução do Programa DRENURBS}

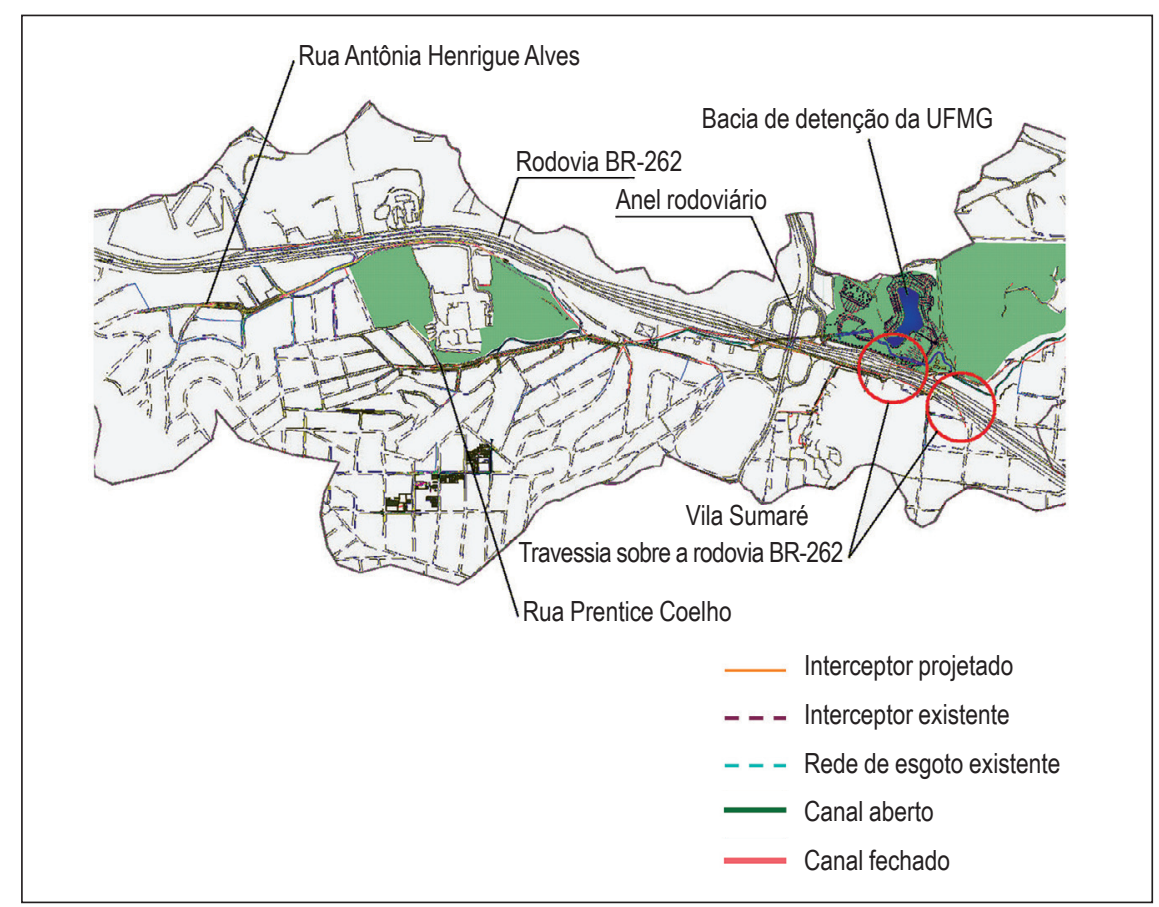

cursos d'água é de 2.810 metros, com uma área de influência de $6 \mathrm{~km}^{2}$ e uma população de aproximadamente 20.000 habitantes. As obras executadas nessa área contemplaram a estabilização de margens e controle de erosôes, implantação dos sistemas de drenagem e de esgotamento sanitário, execução de bacia de detenção de cheias, complementação do sistema viário, construção de áreas de uso social e a desapropriaçáo/indenização e relocalização de 46 famílias. As obras foram iniciadas em 2009 e concluídas em 2011 e hoje contribuem para minimizar os efeitos das inundaçôes no campus da Universidade Federal de Minas Gerais (UFMG) e no Aeroporto da Pampulha (Aroeira, 2010), conforme mostra a Figura 1.

Há de se observar que, ao longo da implantação das intervençóes do DRENURBS, a participação da população contribuiu para o sucesso dos objetivos

direita do Ribeirão do Onça, uma das principais bacias pertencentes ao Município de Belo Horizonte, tributária do Rio das Velhas, que por sua vez, é afluente à montante do Rio São Francisco. Cabe mencionar ainda três microbacias que despejam no Engenho Nogueira: as do Córrego Cascatinha, da Rua Prentice Coelho e da Avenida Antônio Henrique Alves (com montante já canalizada, transformando-se na avenida Pandiá Calógeras). do programa, mas, certamente, devido à complexidade de interesses envolvidos, trouxe também questionamentos que podem revelar as fragilidades de tal processo. É de se indagar, portanto, se, apesar dos conflitos de interesses existentes entre gestores públicos, sociedade civil e setor privado, seriam eles capazes de perseguir objetivos coletivos, cada um do seu jeito, mas navegando na mesma direção, e se esses esforços convergiriam para um propósito comum.

A execução do quarto empreendimento do DRENURBS, o da Bacia do Córrego Engenho Nogueira, tornou mais evidentes as limitações na implantação do programa. Pode-se supor que essas limitaçôes resultem da diferença de extensão entre as três primeiras sub-bacias que receberam intervenção do DRENURBS - que são cerca de dez vezes menores ${ }^{6}$ - e as bacias dos córregos Engenho Nogueira e Bonsucesso. No entanto, ao que parece, não é apenas o tamanho das bacias que tem dificultado a consolidação da nova proposta para a gestão das

\footnotetext{
${ }^{6} \mathrm{Aárea}$ total de drenagem das bacias dos córregos $1^{\circ}$ de Maio, Baleares e Nossa Senhora da Piedade é de respectivamente, $0,48 \mathrm{~km}^{2}, 0,43 \mathrm{~km}^{2}$ e $0,73 \mathrm{~km}^{2}$, enquanto a do Córrego Engenho Nogueira é de $9,90 \mathrm{~km}^{2}$ e do Córrego Bonsucesso, de 11,92 $\mathrm{km}^{2}$ (PRÁXIS, 2003).
} 


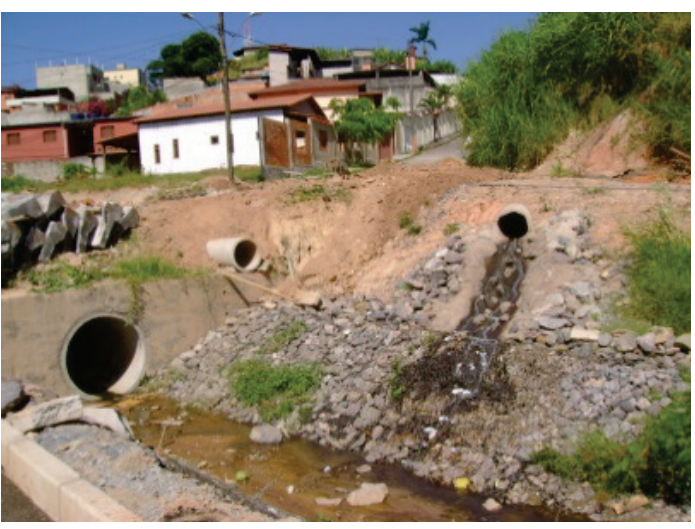

águas, mas também a diversidade das intervençôes (realizadas simultaneamente e em pontos diferentes) necessárias para minimizar os efeitos negativos da poluição hídrica e das inundaçóes especificamente na bacia do córrego em questâo. Tal complexidade, que engloba características socioespaciais e econômicas diferentes e também interesses divergentes, pode ter sido um dos desafios enfrentados pelo DRENURBS.

Além disso, o intervalo entre a aquisição do financiamento, em 2004, e a implementação dos empreendimentos, a partir de 2007-2008, levou à abdicação de alguns itens do projeto, como a criação de um parque linear na Bacia do Córrego Engenho Nogueira. Segundo o gerente executivo do programa, isso ocorreu em virtude da reduçáo dos recursos causada pela desvalorização do dólar (Aroeira, 2010).

Contudo, não se pode afirmar que a questão financeira tenha sido o principal entrave ao desenvolvimento do DRENURBS nesta área. É o que se depreende de um relatório produzido pelo Núcleo Integrado Cascatinha (2011), uma associação civil de direito privado que desenvolve atividades de mobilização social e educação ambiental formal e não formal integrada com diversos atores sociais e em parceria com entidades públicas e privadas. Tais atividades visam à preservação do meio ambiente e à melhoria da qualidade de vida local, baseadas na recuperação e conservação da sub-bacia hidrográfica do Córrego Engenho Nogueira. Seus membros integram a Comissão DRENURBS, participando permanentemente das discussóes que dizem respeito ao Projeto de Revitalização daquela bacia.

$\mathrm{O}$ relatório, elaborado e entregue à equipe do DRENURBS, baseou-se em visitas técnicas às frentes de obras, quando foram feitos coleta de depoimentos
FIGURA 2: Lançamento de esgoto na margem do canal aberto no córrego da Rua Prentice Coelho. Fonte: Acervo do Núcleo Integrado Cascatinha (2011).

das comunidades ribeirinhas e registro fotográfico, e na reunião posterior dos seus integrantes, com o objetivo de comparar o projeto inicial do empreendimento de tratamento de fundo de vale do córrego e as intervençôes efetivamente realizadas pela Prefeitura de Belo Horizonte.

O documento traz as preocupaçōes do grupo em relação à efetiva implantação de todas as intervençóes projetadas, após o anúncio, pelo DRENURBS, de conclusão das obras no primeiro semestre de 2011. Ele questiona a forma pela qual o empreendimento estava sendo implantado, suas consequências na vida da comunidade local, e, ao levar em conta os objetivos do próprio programa, abre um leque de discussóes sobre intervençóes para melhorias no espaço urbano. O relatório aborda vários problemas, entre os quais, falhas no atendimento das condicionantes ambientais determinadas pelo órgão ambiental do município ${ }^{7}$; falta de medidas mitigadoras na implantação das obras, que, devido à intensa movimentação de terra, em época de chuvas, causou transtornos em outros pontos da bacia; presença de taludes ainda com solo exposto, recaindo sobre as margens de um dos córregos e de efluentes comerciais lançados diretamente em suas águas (Figura 2); inexistência de área de uso social e paisagístico ou de convivência implantada; e permanência, em alguns trechos da sub-bacia, de esgoto, lixo e entulho.

Diante das questóes apresentadas no relatório do Núcleo Cascatinha, pode-se constatar que algumas das dificuldades encontradas na implantação do

\footnotetext{
${ }^{7}$ Não foi apresentado, por exemplo, o projeto de recuperação vegetal para a bacia hidrográfica.
} 
DRENURBS na Bacia do Córrego Engenho Nogueira decorreram da reduçáo dos recursos financeiros, mas elas vão além disso, pois expóem falhas na própria execução das obras, com até mesmo certo impacto ambiental que preocupou o grupo. Esse fato, por sinal, é relevante, considerando-se que o programa tem um cunho ambiental, e mostra que, apesar da concepção inovadora do DRENURBS, sua implantação ainda tem que avançar para consolidar-se de fato como referência de revitalização de bacias/sub-bacias hidrográficas.

Por outro lado, a leitura de outro documento, o "Diagnóstico de Percepção Socioambiental Ex-post", elaborado pela equipe de educação ambiental do DRENURBS, mostra uma avaliação bastante positiva sobre as atividades educativas previstas no programa para essa bacia. Segundo esse documento, a "comunidade é bastante engajada, destacando o papel da Comissão DRENURBS que acompanhou as intervençóes, além de participar da elaboração e implementação do PLEA [Plano Local de Educaçáo Ambiental]”. O diagnóstico reconhece também o envolvimento das escolas nas atividades do PLEA, com o engajamento de alunos e professores nas questóes socioambientais da regiáo, dispostos a funcionar como agentes multiplicadores, e ainda que "as modificaçóes no projeto inicial a ser executado pelo Programa DRENURBS tenha causado certa insatisfação, muitas pessoas continuaram atuantes nas atividades de educação ambiental" (PBH/FUNDEP, 2011, p. 22).

É, portanto, nesse contexto de avanços, dificuldades e impasses decorrentes da intervenção no espaço urbano pelo Poder Público, que se torna importante refletir sobre as bases de uma mudança de paradigma na gestão de bacias hidrográficas. É necessário pensar sobre o tipo de projeto que será continuamente (re) construído, na (re)composição junto às comunidades, de um cenário de (re)apropriação do espaço que possa promover a iniciativa e o envolvimento das mesmas, favorecendo o empoderamento, para que elas também se sintam responsáveis pelas transformaçóes ocorridas.

De acordo com Medeiros (2009), o programa considera vários aspectos de saneamento ambiental, na tentativa de aprimorar as condiçóes de vida da população local, tratando-se de uma proposta diferenciada de intervenção no espaço urbano, que procura constituir outro modo de gerir os cursos d'água que ainda se encontram em leito natural na cidade de Belo Horizonte, em busca de uma gestáo integrada.

Macedo também avalia que "pode-se concluir que o Drenurbs tem uma proposta de implantar um sistema de drenagem sustentável dentro da realidade de cada bacia nele inserido, adaptando as técnicas de restauração disponiveis, caso a caso [...]. Deve-se também ressaltar que é muito raro que um município assuma este tipo de proposta como política pública, através de um planejamento em longo prazo" (Macedo, 2009, p. 104).

Além das dificuldades encontradas na implantação do Programa DRENURBS na Bacia do Córrego Engenho Nogueira, percebe-se também em Belo Horizonte a existência de contradiçôes importantes na gestão de suas águas, conforme já destacado na referência à cobertura do canal do Ribeirão Arrudas. A seguir, levantaremos alguns pontos dessa contradição para reflexão.

\section{PROJETO BOULEVARD ARRUDAS: RETROCESSO NA GESTÃO DAS ÁGUAS URBANAS}

A primeira obra para canalização do trecho do Ribeirão Arrudas inserido na malha urbana iniciou-se nos anos de 1920 e foi finalizada na década de 1940 , sob a administração do então prefeito Juscelino $\mathrm{Ku}$ bitschek. A intervenção foi indicada, naquela época, como a opção adequada para solucionar tanto os problemas sanitários quanto os relativos às frequentes enchentes que afligiam a capital.

Posteriormente, após a ocorrência de inundações no período chuvoso de 1977-1978, foram retomadas as intervençóes estruturantes no canal do Arrudas (Fundação João Pinheiro, 1997). Belo Horizonte foi então considerada o maior canteiro de obras do Brasil e seus agentes políticos prometiam a eliminação das graves consequências provocadas pelas inundaçôes urbanas (Rodrigues, 1981). Entretanto, devido à carência de recursos públicos em um contexto de crise financeira mundial, as obras de retificação do curso d'água foram efetuadas lentamente, e, em janeiro de 1983, elas encontravam-se paralisadas quando uma nova inundação atingiu o Arrudas. Naquele ano, a prefeitura acelerou o processo de canalização do ribeirão, implantando inclusive uma via urbana, no sentido leste-oeste, que era considerada prioritária no sistema viário proposto pela PLAMBEL - Superintendência de Desenvolvimento da Região Metropolitana (Fundação João Pinheiro, 1997).

Em anos mais recentes, entretanto, constatou-se que a opção pela canalização não resolve os problemas das enchentes e inundaçốes e, muitas vezes, pode até mesmo agravá-los, já que a retificação dos córregos 


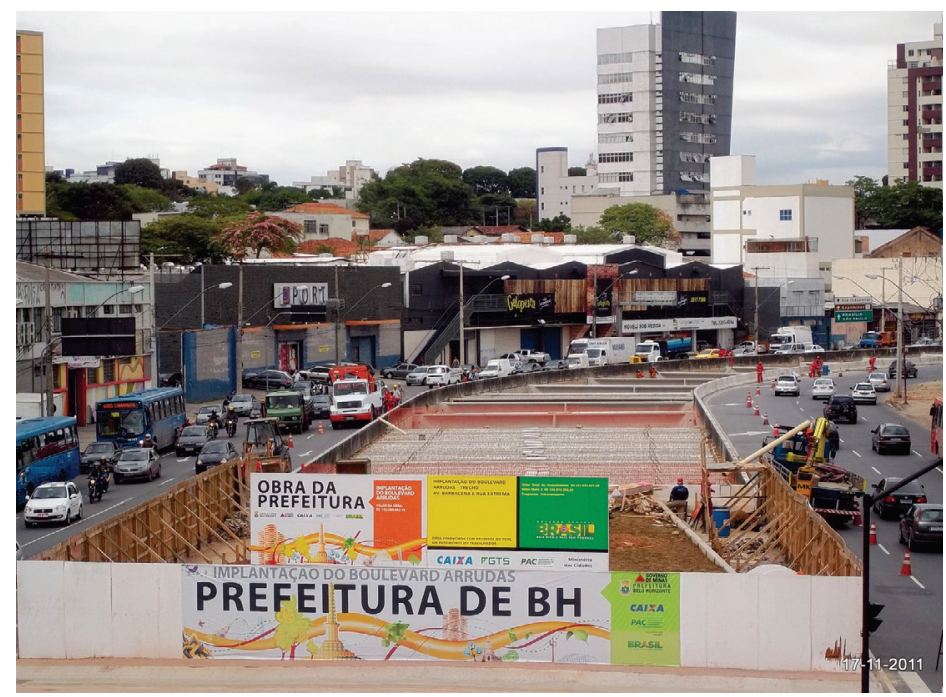

FIGURA 3: Obra de execução do Boulevard Arrudas (Trecho V). Fonte: Acervo da PBH. e rios, desviando-os de seus leitos naturais, aumenta a velocidade da água e, consequentemente, causa inundaçôes à jusante em função da maior vazão dos mesmos. Também a ocupação irregular das margens dos córregos, a impermeabilização do solo e a retirada da cobertura vegetal potencializam os riscos.

Assim, a partir da constatação dos efeitos negativos da canalização e com a disseminação de novas alternativas para o tratamento e gestão das águas urbanas, outras experiências foram ganhando espaço. Um dos casos mais exemplares nesse sentido foi a restauração do Rio Cheonggyecheon, no centro de Seul, Coréia do Sul, com a sua descanalizaçáo após 20 anos da construçâo de uma autoestrada sobre o seu leito, por onde passavam cerca de oito mil carros. O projeto foi concluído em 2006 e uma importante área de lazer entregue à população (Noh, 2010).

Mas no caso de Belo Horizonte, apesar do sucesso das intervenções do DRENURBS, acompanhou-se, simultaneamente à sua implantação, o fechamento do canal do principal ribeirão que atravessa a cidade.

Ressalte-se ainda que as diretrizes relativas à drenagem urbana postas pela Lei 8.260/01, que instituiu a Política Municipal de Saneamento, também não foram suficientes para evitar o fechamento do Arrudas, mesmo indicando a busca por "soluçôes que viabilizem a reabertura de canais fluviais, a partir da concepção e execução de intervençōes para adequação elou recuperação dessas galerias, assegurando também sua integração à paisagem urbana, a mitigação dos impactos ambientais e a melhoria das suas condiçóes de manutenção" (CMBH, 2001, art.9).

O empreendimento denominado Boulevard Arrudas teve a primeira etapa (trecho situado entre a Avenida dos Andradas, Alameda Ezequiel Dias e Rua Levi Carneiro) indicada como uma extensão do projeto da "Linha Verde"; e os demais trechos foram apresentados como parte das açóes de melhoria da mobilidade urbana planejados pela Prefeitura de Belo Horizonte para a Copa de 2014, já que a cidade é uma das sedes do mundial de futebol que acontecerá no Brasil. Na intervenção, estão sendo realizados trabalhos de recuperação estrutural da laje de fundo, recobrimento da canalização, implantação de canteiro central elevado, demolição e reconstrução dos passeios para adequação às normas de acessibilidade e de novas pistas de rolamento, construçáo de ciclovia, recuperação e ampliação da drenagem pluvial, implantação de postes de iluminação pública e sinalização de trânsito e paisagismo (BHTRANS, 2010). Atualmente, encontra-se em execução o quinto trecho da obra, entre a Avenida Barbacena e a Rua Extrema (ver Figura 3), que é financiado com

\footnotetext{
${ }^{8} \mathrm{~A}$ Linha Verde é um projeto do governo de Minas Gerais que abrangeu a realização de um conjunto de obras viárias, para construir uma via de transito rápido ligando o centro de Belo Horizonte ao Aeroporto Internacional Tancredo Neves, passando pelo complexo de prédios da Cidade Administrativa de Minas Gerais (CAMG), para onde a sede do governo e as secretarias estaduais migraram.
} 
recursos do Programa de Aceleração do Crescimento (PAC), do governo federal.

$\mathrm{Na}$ exposição sobre os benefícios do empreendimento, representantes da prefeitura apresentaram o projeto como uma nova saída para a cidade, enfatizaram sua importância para a "viabilização do trânsito" e disseram até que ele teria de ser executado por uma "questão de higiene", em razão de um restaurante popular que fica situado próximo ao local. (BHTRANS, 2010).

O que fica evidente, na defesa do Boulevard Arrudas, é a preocupação em remediar a situação de degradação do rio, resultante da poluição de suas águas, sem, no entanto, demonstrar qualquer interesse em tratar as causas dessa poluição. A solução apresentada exclui o rio da paisagem urbana e apresenta como compensação, a melhoria da mobilidade urbana.

Nessa mesma direção, qual seja, a de evidenciar as compensaçóes para os danos ambientais resultantes da cobertura do rio, a Empresa de Transporte e Trânsito de Belo Horizonte (BHTRANS) esclarece que o Boulevard Arrudas terá o alargamento das vias como ganho principal, possibilitando a instalação de mobiliário urbano e a implantação de faixas preferenciais para o transporte coletivo, além do tratamento significativo de passeios, tornando-os mais acessíveis à circulação de pedestres. Outro benefício citado pela BHTRANS é a iluminação da pista de rolamento no canteiro central e dos passeios. De acordo com a empresa, "esses ganhos ambientais são possíveis a partir da construçâo de laje sobre todo o trecho em questão do canal, no vetor leste oeste. As obras também incluem um projeto de paisagismo, com a plantação de quase 600 árvores" (BHTRANS, 2010. Grifo nosso).

Essa afirmação - de que a construção de laje sobre o canal traz ganhos ambientais para a cidade - faz-nos refletir sobre o desenvolvimento ambiental e, mais especificamente, sobre a gestão de águas em Belo Horizonte. O que se observa é que mesmo que o Arrudas seja um rio urbano já totalmente poluído, o fechamento do canal dificulta o resgate de sua história como cenário de vida existente há décadas e torna cada vez mais distante a possibilidade de sua revitalização.

Assim, o que constatamos atualmente em Belo Horizonte é um aparente consenso entre duas concepçóes completamente contraditórias. Por um lado, avança-se rumo a um novo paradigma para a gestão das águas, com uma legislação pioneira e até mesmo a implantaçáo de um programa como o DRE-
NURBS; por outro, a implantação da cobertura do canal do Ribeirão Arrudas caracteriza um retrocesso, porque adota um modelo ultrapassado, que valoriza prioritariamente o sistema viário e encerra de vez a possibilidade de revitalização do rio.

A seguir, será feita uma avaliação geral sobre essa simultaneidade de açóes, tão díspares, na gestão das águas urbanas de Belo Horizonte.

\section{IMPASSES NA IMPLANTAÇÃO DE UM NOVO PARADIGMA}

Entende-se que haja impasses para a consolidação de experiências alternativas ao modelo dominante de desenvolvimento urbano, na gestão de águas ou de quaisquer outras políticas públicas. No caso de Belo Horizonte, as inovaçôes na gestão das águas encontram resistências e obstáculos de natureza cultural, política, técnica, financeira, social, entre outras.

$\mathrm{O}$ primeiro aspecto a ser abordado diz respeito à dificuldade de se realizar mudanças culturais. Se, por um lado, os profissionais de engenharia não inovam nas técnicas de revitalizaçáo, por outro, parte da população ainda acredita que é melhor canalizar o rio para minimizar as ocorrências de inundaçôes urbanas e de doenças relacionadas à contaminação das águas.

A engenharia sanitária, durante anos, apresentou a canalização dos cursos d'água como a solução adequada para as águas urbanas. Com isso, a relação da população com as águas foi sendo modificada e cada vez mais demarcada pela exclusão das mesmas da paisagem urbana. A relação homem-rio deixou de ser pensada a partir da possibilidade de recuperaçáo da qualidade da água, já que o meio urbano é local de desenvolvimento e efluentes indicam o preço que se paga pelo progresso. A compensação foi a construção de avenidas sanitárias, para permitir a viabilização do trânsito e a higienização da cidade.

No entanto, estudos acabaram por demonstrar que tal concepção é inadequada, embora ainda exista parcela importante de engenheiros hidráulicos que continuam a buscar soluçôes estruturais que alteram o meio ambiente com excesso de áreas impermeabilizadas (Tucci, 2004). Essa situação indica a necessidade de uma atualização na formação acadêmica desses profissionais, com estudos sobre uma gestáo das águas que favoreça a integração entre os ecossistemas naturais, o sistema urbano artificial e a sociedade.

A falta de conhecimento generalizada sobre as técnicas de drenagem urbana por parte expressiva da 
população também é um problema. Por isso é que a construção de avenidas sanitárias é quase sempre uma demanda da população que vive no entorno dos cursos d'água. Os moradores ribeirinhos, muitas vezes, têm uma imagem negativa dos rios e córregos urbanos, devido à convivência com a água poluída. Nesse caso, o trabalho de educação ambiental é fundamental para uma melhor compreensão da complexidade da relação entre o homem e a natureza.

Cabe considerar, no entanto, que a construção de uma nova cultura é um processo amplo e gradual, que deve iniciar-se pela tentativa dos gestores em obter a confiança dos moradores de que é possível recuperar a qualidade d'água e resgatar uma convivência anterior, quando a água fazia parte do cotidiano dos moradores de áreas urbanas.

Tucci (2004) menciona essencialmente duas dificuldades políticas na construção de um novo modelo de gestão das águas. A primeira é a visão setorial limitada de alguns gestores, separando a implementação de políticas públicas de saneamento ambiental (abastecimento de água e esgoto sanitário) das de drenagem pluvial, resíduos sólidos e saúde pública. Essa perspectiva contrapóe-se às linhas diretrizes da Política Nacional de Recursos Hídricos (Brasil, 1997), que valoriza a gestão integrada. A segunda dificuldade apontada pelo autor está na falta de capacidade gerencial de alguns municípios, cuja estrutura para o planejamento e gerenciamento não é adequada às propostas inovadoras.

A visão setorial limitada, citada por Tucci, está evidente no planejamento e desenvolvimento urbano de Belo Horizonte, considerando-se que tanto o DRENURBS quanto o Boulevard Arrudas são projetos formulados e implantados pela Secretaria Municipal de Infraestrutura e Obras. O primeiro é destinado ao saneamento ambiental e o segundo à melhoria do trânsito, mas não há uma gestão integrada de políticas públicas fundamentais para a sustentabilidade urbana.

As dificuldades referentes ao aspecto técnico sofrem influência do discurso competente (Chauí, 2003), no qual o especialista domina o saber técnico e diz o que é o "correto", inclusive qual deve ser a relaçấo do homem com os cursos d'água urbanos. Assim é que o modelo de tratamento das águas urbanas por meio da canalização foi amplamente defendido por técnicos e especialistas em saneamento, constituindo o discurso dominante na solução para a drenagem urbana.
Ao se optar pela canalização, o que se tem é a exclusão das águas e o uso dos cursos como condutores de esgoto. A construção de avenidas sanitárias é enfatizada como ganho ambiental, capaz de esconder os dejetos, numa dinâmica que distancia cada vez mais o morador urbano das águas que circulam na cidade, sem qualquer debate acerca de sua corresponsabilidade em manter essas águas em condiçóes de uso e contemplação.

Com isso, a canalização, ao se consolidar como modelo dominante, acabou adotada durante muitos anos como única opção para o saneamento, estabelecendo, também para as empreiteiras, as intervençóes que deveriam ser projetadas, por serem consideradas mais adequadas. Esse modelo de gestão das águas é o de mais fácil execução, pois novos projetos exigem inovação técnica e, consequentemente, recursos financeiros diferenciados.

Tem-se aí outro entrave para a implantação de modelos inovadores na revitalização de rios: $\mathrm{o}$ aspecto financeiro. A revitalização do rio em seu leito natural necessita de aumento na largura de suas margens, o que só pode ser feito adequando-se a largura das vias públicas. Em alguns casos, ainda é necessário remover famílias, o que também aumenta os custos. Além disso, cabe mencionar que a estimativa de custos para a revitalização dos cursos d'água urbanos não se limita à operacionalização das obras. Seu sucesso exige um grande investimento na mobilização e educação ambiental da população local, em serviços completos de saneamento ambiental (coleta de lixo e esgoto), na manutenção constante das áreas revitalizadas (infraestrutura de iluminação nos parques lineares, serviço de limpeza urbana, etc.) e em segurança.

Por fim, deve-se trazer à discussão os impasses concernentes ao aspecto social. A necessidade de remoção de famílias para a revitalização dos cursos d'água e de suas margens leva muitas vezes a resistências devido às mudanças significativas que representa na vida da populaçáo remanejada, bem como em relação às alternativas normalmente propostas: a opção pela indenização nem sempre é considerada, por não oferecer um valor justo para o imóvel removido, enquanto a opçáo pelo reassentamento em unidade habitacional verticalizada impóe mudanças no cotidiano das famílias, inclusive com o acréscimo de custos financeiros como, por exemplo, o pagamento da taxa de condomínio.

Entende-se assim que buscar a sustentabilidade urbana como prioridade política corresponde a se propor a enfrentar os diversos impasses que normal- 
mente decorrem da falta de conhecimento acerca dos ganhos reais de uma gestão integrada no saneamento urbano. Muitas vezes, essas intervençóes integradas podem ser, a princípio, mais caras do que a adoção de soluçóes pontuais, como a canalização, para solucionar os problemas de inundaçóes urbanas e saúde pública, mas é certo que elas trazem ganhos muito maiores a médio prazo.

\section{CONCLUSÃO}

Neste artigo, foi possível abordar diversos pontos atinentes à gestão de recursos hídricos no meio urbano, bem como as contradiçóes políticas decorrentes desse processo. Acredita-se que o Programa DRENURBS apresenta avanços significativos como experiência que impóe o questionamento do discurso, até então dominante na gestão das águas urbanas, ancorado na canalizaçấo como solução única para a drenagem.

Entretanto, somente se pode falar da consolidação de um novo paradigma quando se verificam mudanças na ordem estabelecida, no caso, mudanças que configurem um efetivo desenvolvimento socioambiental no uso e ocupação do espaço, inserindo os cursos d'água na paisagem urbana. Porém, ao dividir os investimentos entre a cobertura do canal do Ribeirão Arrudas e os processos de revitalizaçáo implantados nos córregos contemplados pelo DRENURBS, o que se constata é a falta de coerência quanto ao modelo que se quer na gestão dos recursos hídricos de Belo Horizonte. Mesmo com a existência de parecer técnico apontando que a água que corre pelo Arrudas encontra-se poluída e que o "rio" estaria morto, é fundamental sua presença na cidade para reafirmar a urgência de uma mudança cultural e técnica em relação aos cursos d'água existentes, principalmente aqueles que ainda se encontram em seus leitos naturais, até porque sempre existe a possibilidade futura de sua despoluição.

O aparente consenso entre a implantação do Boulevard Arrudas e o desenvolvimento do DRENURBS representa, na verdade, um retrocesso na consolidaçấo de um paradigma inovador, voltado para o desenvolvimento socioambiental da capital mineira. São concepções contraditórias, que não podem ser vistas como projetos possíveis de serem conciliados em uma administração pública que valoriza a sustentabilidade urbana. Além disso, traduz uma fragmentação institucional na gestão das águas, pois caminha em direçôes opostas, com um mesmo discurso do desenvolvimento sustentável.

Ressalte-se também a importância da participação popular no DRENURBS ou em qualquer outro programa de caráter ambiental que se comprometa com inovaçóes e novos paradigmas. É necessário ir além da elaboraçáo da proposta e da eficiência em sua execução técnica e promover uma gestão que incorpore todos os conflitos e contradiçóes presentes no debate, permitindo que também os desprivilegiados falem sobre os seus interesses e expectativas e possam se colocar no cenário, para uma busca por justiça socioambiental. Só dessa forma é possível dizer que suas açóes obtiveram sucesso, ou seja, apenas quando houver uma interação mais justa entre os interesses setoriais do Poder Público, da sociedade civil e do setor privado e entre as esferas ambientais, econômicas, éticas, sociais e culturais.

\section{Referências}

AROEIRA, R. M. 2010. Recuperação ambiental de bacias hidrográficas, Belo Horizonte, Brasil. In: MACHADO, A. T. G. M. et al. (Org.). Revitalização de rios no mundo: América, Europa e Ásia. Belo Horizonte: Projeto Manuelzão, p. 221-240.

BRASIL. 1997. Lei ${ }^{\circ}$ 9.433, de 8 de janeiro de 1997. Política Nacional de Recursos Hídricos. Brasília.

2004. Plano Diretor Participativo: Guia para a elaboração pelos municípios e cidadãos. Brasília: CONFEA, Ministério das Cidades.

BHTRANS. Empresa de Transporte e Trânsito de Belo Horizonte. 2010. Boulevard Arrudas melhora mobilidade urbana. Disponível em: http://bhtrans.pbh.gov.br/portal/page/portal.

BRITTO, A. L.; BARRAQUÉ, B. 2008. Discutindo gestão sustentável da água em áreas metropolitanas no Brasil: reflexões a partir da metodologia européia Water 21. Cadernos Metrópole, sem. 1 p. 123-142.

CÂMARA MUNICIPAL DE BELO HORIZONTE (CMBH). 1996. Lei ${ }^{\circ}$ 7.165, de 27 de agosto de 1996. Plano Diretor do Município de Belo Horizonte. Belo Horizonte.

2001. Lei $n^{\circ} \mathbf{8 2 6 0}$, de 03 de dezembro de 2001. Política de Saneamento do Município de Belo Horizonte. Belo Horizonte. 
CHAUÍ, M. 2003. Cultura e democracia: o discurso competente e outras falas. São Paulo: Cortez.

COSTA, H. S. M.; BONTEMPO, V. L.; KNAUER, S. 2008. Programa DRENURBS: uma discussão sobre a constituição de alianças de aprendizagem na Política de Saneamento de Belo Horizonte. In: Encontro Nacional de Estudos Populacionais, 16, 2008, Caxambu. Anais eletrônicos... Caxambu: ABEP.

FUNDAÇÃO JOÃO PINHEIRO. 1997. Saneamento básico em Belo Horizonte: trajetória em 100 anos. Belo Horizonte.

MACEDO, D. R. 2009. Avaliação de Projeto de Restauração de Curso d’água em Área Urbanizada: estudo de caso no Programa Drenurbs. Dissertação (Mestrado em Geografia). Instituto de Geociências, Universidade Federal de Minas Gerais. Belo Horizonte.

MEDEIROS, I. H. 2009. Programa Drenurbs/Nascentes e Fundos de Vale: potencialidades e desafios da gestão sócio-ambiental. Dissertação (Mestrado em Geografia). Instituto de Geociências/Universidade Federal de Minas Gerais. Belo Horizonte.

NASCIMENTO, N. O.; HELLER, L. 2005. Ciência, tecnologia e inovação na interface entre as áreas de recursos hídricos e saneamento. Engenharia Sanitária e Ambiental, v.10 n.1 p. 36-48. Belo Horizonte.

NOH, H. S. Rio Cheonggyecheon: Seul, Coreia do Sul. 2010. In: MACHADO, A. T. G. M. et al. (Org.). Revitalização de rios no mundo: América, Europa e Ásia. Belo Horizonte: Projeto Manuelzão, p. 292-304.

NÚCLEO INTEGRADO CASCATINHA. 2011. Relatório de visita às obras de revitalização da sub-bacia do Córrego Engenho Nogueira. Belo Horizonte.

PRAXIS, Projeto e Consultoria. 2003. Estudo de Impacto Ambiental do Programa DRENURBS. Belo Horizonte.

PREFEITURA MUNICIPAL DE BELO HORIZONTE (PMBH). 2000. Plano Diretor de Drenagem Urbana de Belo Horizonte. Superintendência de Desenvolvimento da Capital. Belo Horizonte.

2002. Programa de Recuperação Ambiental de Belo Horizonte. Secretaria Municipal de Políticas urbanas. Belo Horizonte.

PREFEITURAMUNICIPAL DE BELO HORIZONTE/FUNDAÇÃO DE DESENVOLVIMENTO DAPESQUISA(PMBH/FUNDEP). 2011. Diagnóstico de percepção socioambiental da equipe de educação ambiental ex-post da bacia do córrego Engenho Nogueira. Belo Horizonte. RODRIGUES, C. 1981. História de Belo Horizonte: duas épocas. Belo Horizonte.

SOUZA, M. L. de. 2001. Mudar a cidade: uma introdução crítica ao planejamento e à gestão urbanos. 5 Ed. Rio de Janeiro: Bertrand Brasil. TUCCI, C. E. M. 2004. Gerenciamento integrado das inundações urbanas no Brasil. Revista de Gestão de Águas da América Latina (REGA), v.1, n.1 p. 59-74. Santiago, Chile.

Valdete Lima Bontempo Mestre em Sociologia pela Universidade Federal de Minas Gerais, Brasil. E-mail: valdete.bontempo@pbh.gov.br

Cindy Olivier Programa de Pós-Graduação em Geografia, Universidade Federal de Minas Gerais, Brasil. E-mail: cindy_olivier@hotmail.com

Carla Wstane de Souza Moreira Núcleo Integrado Cascatinha; Programa de Pós-Graduaçáo em Geografia, Universidade Federal de Minas Gerais, Brasil.

E-mail: carlawstane@gmail.com

Gabriel Oliveira Programa de Pós-Graduação em Geografia, Universidade Federal de Minas Gerais, Brasil. E-mail: gabrielt.oliveirab@gmail.com 